Distribution Category: Atomic, Molecular, and Chemical Physics (UC-411)

ARGONNE NATIONAL LABORATORY

9700 South Cass Avenue

Argonne, Illinois 60439

ANL/APS/TB--9

DE93 008834

ANL/APS/TB-9

APS Sector Layout: Utilities, etc.

\author{
by S. Davey \\ Experimental Facilities Division \\ Advanced Photon Source
}

February 1993

DISTRIBUTION OF THIS DOCUMENT IS UNLIMTIED

work sponsored by

U.S. DEPARTMENT OF ENERGY

Office of Energy Research 


\section{APS SECTOR LAYOUT: Utilities, etc.}

This bulletin describes the general physical layout of the APS Experiment Hall and the utilities that will be available for the beamlines.

\section{APS Storage Ring}

The Storage Ring has 40 sectors, of which six are used for accelerator functions. This leaves 34 sectors for extracting synchrotron radiation. Each sector consists of a bending magnet (BM) beamline and a straight section for an insertion device (ID) beamline. Sixteen of these 34 sectors will be ready when the current construction project is completed in 1995. The height of the particle beam and the resulting radiation beams is 1.4 meters from the experimental floor. The layout of the Storage Ring is shown in Fig. 1.

\section{EXPERIMENT HALL - SECTORS \& BEAMLINES}

A sector is composed of a bending magnet source and an adjoining insertion device source. The boundaries of each of the sectors are the storage ring ratchet wall, the main aisle (around the Experiment Hall), and an egress aisle. The Experiment Hall is clear of obstructions up to 21 feet above the experimental floor. The sectors are labeled as shown in Fig. 1, and the first sector is east of the Early Assembly Area (EAA).

The Experiment Hall floor and the storage ring are mechanically isolated from the building walls, the roof, the main aisle, and the mechanical mezzanine (see Fig. 2). These slab on grade floors are placed on stiff in-situ clays and compacted gravel base course material that effectively dampens vibrations. The isolation joint separating the Experiment Hall from the main aisle defines part of the sector boundary. The

The Experimental Hall floor can sustain uniform loads of 250 psf or concentrated loads of up to 2,000 pounds on a $20 \mathrm{in}^{2}$. The concrete floor is coated with an epoxy paint.

The distance along the $\mathrm{BM}$ beamline from the ratchet wall to the sector boundary is 56.05 meters. The distance along the BM beamline from the center of the source to the sector boundary 77.4 meters. The distance along the ID beamline from the ratchet wall to the sector boundary is 55.03 meters. The distance along the ID beamline from the center of the 5-meter straight section to the sector boundary is 79.4 meters.

Details of the layouts were provided in CAD drawings to the CATs in 1992 and updates will be made available (see Fig. 3). 
Access to the storage ring and the beamline front ends from the Experiment Hall floor is through "ratchet doors." These ratchet doors open by sliding out parallel to the beamlines. Space must be reserved for opening the door and operating the door drive mechanism. This is shown in detail on the Experiment Hall layout provided to the CATs. The ratchet doors for the BM front ends are located at the end of the egress aisles. To assure equipment access to the ID beamline front ends for maintenance, etc., a portion of the BM beam transport must be readily removable. Hutch walls, heavy equipment, or difficult to align equipment should not be located in this area.

A sector must also provide for means of egress. The egress aisles also provide for front end access. The Experiment Hall of the APS will conform to the requirements of the Life Safety Code including: 1) the maximum travel distance to an exit will be 400 feet, and 2) the maximum length of dead end pockets will not exceed 50 feet. For example, this may require beamline "duckunders" that have a 4-foot clearance and are connected to an egress aisle. Egress aisles are 1 meter wide and are to remain free and clear of any obstructions.

The top of the storage ring tunnel can be reached from the experimental floor by ladders. These ladders are located in the egress aisles and the BM ratchet doors slide behind them.

\section{SPACE FOR VIBRATION-PRODUCING EQUIPMENT}

There may be situations in which the users would like to isolate vibrationproducing heavy equipment from the experimental floor. For such situations, opportunities exist in the acoustically treated mechanical mezzanine. This area is mechanically isolated from the experimental floor and the space available in every other sector is $\approx 130 \mathrm{ft}^{2} / 2$ sectors $\approx 16 \mathrm{ft} \times 8 \mathrm{ft} \times 9 \mathrm{ft}$ (high) $/ 2$ sectors. There are stairs located in the main aisle for personnel access. Equipment access is through trap doors distributed around the ring and located in the ceiling of the main aisle. 


\section{Utility Specifications}

The locations of some of the APS conventional facilities utility taps for two typical Experimental Hall sectors are shown in Fig. 4.

\section{ELECTRICITY}

The electrical power for each sector will distributed from four distribution panels. Two of these panels are for the BM beamline, and two are for the ID beamline. One panel supplies clean power, and one supplies utility power.

Each of the four panels distribute $30 \mathrm{kVA} 120 / 208 \mathrm{~V}$. Beamline distribution panels (and the corresponding transformers) are located on building columns located at the main aisle adjoining the sector. A grounding buss is located in the Experiment Hall on the wall of the mechanical mezzanine (see Fig. 3)..

WATER

\section{DEIONIZED WATER}

Deionized (DI) water is typically used as the primary supply for heat exchangers. Because this water is used by the entire APS, it is essential to maintain the integrity of the DI water. Some materials such as iron, brass, or bronze shall not be used in the DI plumbing system. Hence, users must seek APS approval prior to DI water hookup.

The supply of DI water is provided at every other sector and is located on the mechanical mezzanine wall. The DI water is supplied at a temperature of $75^{\circ}$ $\pm 1.8^{\circ} \mathrm{F}\left(24 \pm 1^{\circ} \mathrm{C}\right)$. A typical return water temperature will be $90^{\circ} \mathrm{F}\left(32^{\circ} \mathrm{C}\right)$. The pressure of the DI water supply to users is $150 \mathrm{psig}$, and the return pressure should be $\geq 40$ psig. The flow rate per sector (with uniform diversity in the Experiment Hall) is $10 \mathrm{gpm}$, which is equal to $0.75 \times 10^{5} \mathrm{Btu} / \mathrm{hr}(22 \mathrm{~kW})$.

\section{Chilled Water}

A typical application for chilled water is for heat exchangers or as the cooling coil supply in an air handling unit. Chilled water taps are located in the mechanical mezzanine at every other sector and are supplied to capped valves. Chilled water is supplied at a temperature of $41^{\circ} \pm 1.5^{\circ} \mathrm{F}\left(5 \pm 0.8^{\circ} \mathrm{C}\right)$, and the maximum return temperature should be no greater than $60^{\circ} \mathrm{F}\left(16^{\circ} \mathrm{C}\right)$. The chilled water pressure will vary and will be a function of location, flow rate, demand, etc. The maximum pressure of the chilled water supply will be 100 
psig, and the minimum supply pressure will be 30 psig. For constant pressure, the user should supply a booster pump. The return pressure will be $10 \mathrm{psig}$. The flow rate per sector (with uniform diversity) is $65 \mathrm{gpm}(180 \mathrm{~kW})$.

\section{HEATED WATER}

A typical application for hot water is as a supply in an air handling unit. There will be situations in which stations will need air exchange with the outside. During cold weather, this may require heating the outside air. Hot water taps are located in the mechanical mezzanine at every other sector and are supplied to capped valves. Hot water is supplied at a temperature of $230^{\circ} \mathrm{F}$ $\left(110^{\circ} \mathrm{C}\right)$. The return water temperature will be $170^{\circ} \mathrm{F}\left(77^{\circ} \mathrm{C}\right)$. The hot water pressure will vary and will be a function of location, flow rate, demand, etc. The maximum pressure of the hot water supply will be $110 \mathrm{psig}$, and the minimum supply pressure will be 50 psig. The return pressure will be 25 psig. The flow rate per sector (with uniform diversity) is $20 \mathrm{gpm}$ at each location, which is equal to $0.6 \times 10^{6} \mathrm{Bcu} / \mathrm{hr}(175 \mathrm{~kW})$.

AIR

\section{COMPRESSED AIR}

A typical application for compressed air is as a pneumatic gate valve supply. One compressed air connection is available at every sector and is located on the mechanical mezzanine wall. The pipes are $3 / 4$ inch in diameter. The pressure of the compressed air system is $130 \pm 5$ psi and varies with location and demand. The maximum flow rate is $40 \mathrm{CFM}$ per sector.

\section{ChILled AIR}

A typical application for chilled air is air conditioning the hutches. Taps are uniformly distributed in the Experiment Hall at 108 places. The taps are located near the ceiling over the Experiment Hall, and chilled air can be easily connected to experimental stations in every sector. The supply temperature is $48^{\circ} \mathrm{F}\left(9^{\circ} \mathrm{C}\right)$. The relative humidity will be kept to less than $95 \%$. The maximum flow rate per tap (with uniform diversity) is $5000 \mathrm{CFM}$, which is equal to $0.15 \times 10^{6} \mathrm{Btu} / \mathrm{hr}(42 \mathrm{~kW})$. The flow to the Experiment Hall is 72,000 CFM [or 2 X10 6 Btu/hr $(615 \mathrm{~kW})]$.

\section{EXHAUST}

The capability to exhaust hazardous gases will be needed in white beam stations. Roof penetrations have been provided to handle any kind of exhaust requirements. 


\section{COMMUNICATION}

The communication equipment to be installed in the Experiment Hall will be specified at a later date to take advantage of the latest available technology. The network will be multiple FDDI with an ethernet segment per sector and a speed of $100 \mathrm{Mbit}$ that can be upgraded to Gbit rates. The bridges will be located in a secured closet in the Lab/Office Modules. 


\section{Figure Captions}

Fig. 1 Plan view of the Advanced Photon Source (APS)

Fig. 2 Plan view of APS sectors. Each sector consists of a bending magnet (BM) beamline and a straight section for an insertion device (ID) beamline. The APS has 34 sectors available for extracting synchrotron radiation. The inset in the lower left corner of the figure shows the first few sectors. The sectors are sequentially number starting with the first sector east of the Early Assembly Areas.

Fig. 3 Elevation of the APS Experimental Hall, the main aisle, and the mechanical mezzanine.

Fig. 4 Plan view of APS conventional facilities utility tap locations for two typical experimental hall sectors. 


\section{PLAN VIEW OF THE ADVANCED PHOTON SOURCE}

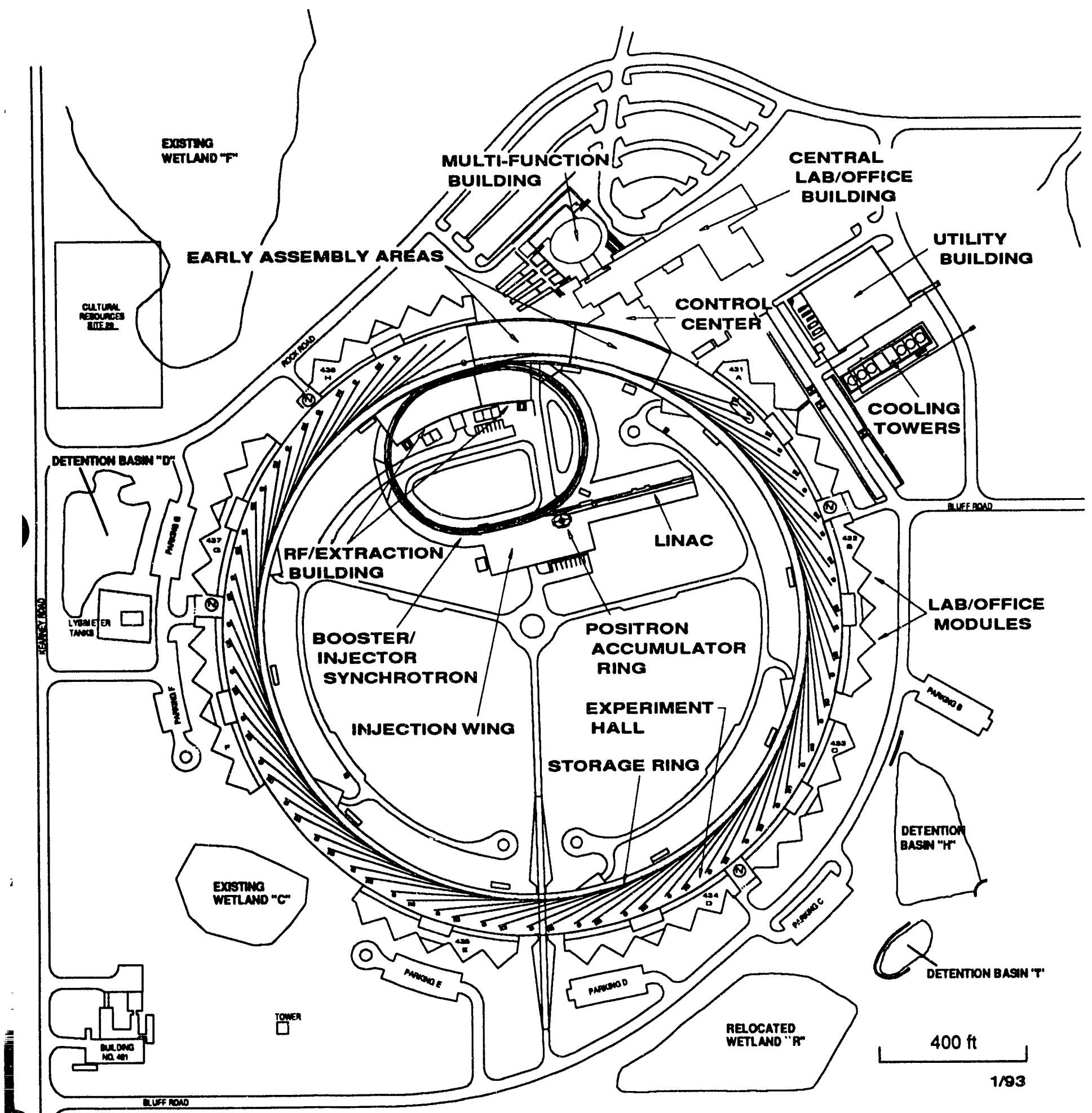




\section{LEGEND.}

D CENTER POINI OF SM STRAIGHT SECHON

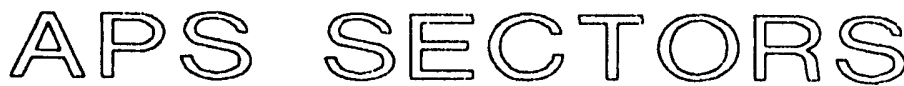

$\triangle$ SOURCE PONT OO GENDINC, MAGNCT BEAMLINE

LABEL
\begin{tabular}{|l|l}
\hline 01 & \\
\hline 02 & \\
\hline 03 & \\
\hline 04 & \\
\hline 05 & $\vdots$ \\
\hline 06 & $\vdots$ \\
\hline
\end{tabular}

RACHET WALL

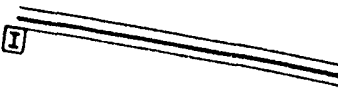

"KEEP CLEAR" AREA FOR OPERATION OF DOOR WNCH

DO NOT LOCATE HUTCH OR LARGE BEAMLINE. DEVCES HERE. PREPARE TO REMOVE BEAM PIPE FOR ACCESS TO FRONTEND DOOR

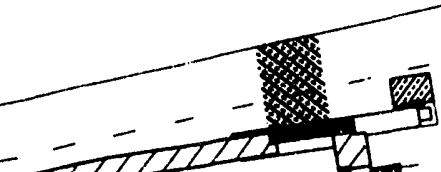

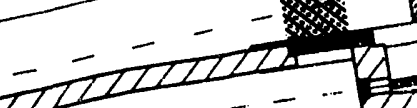

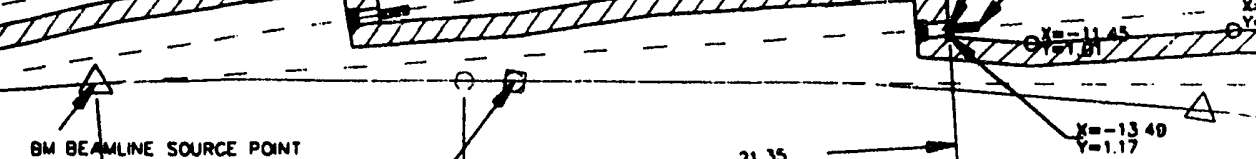

BM BECMLINE SOURCE PONT

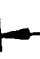

Sm 10 SOURCE PONT

TO 5 JACE P1.3S PONT ON BM.

$24.392 \mathrm{~m}$ (TO SOURCE POINT, CENTER OF STRAIGHT SECTION)
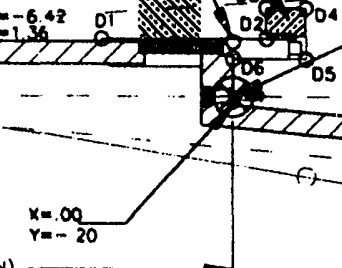

ORIGIN $(\times 0, Y 0)$

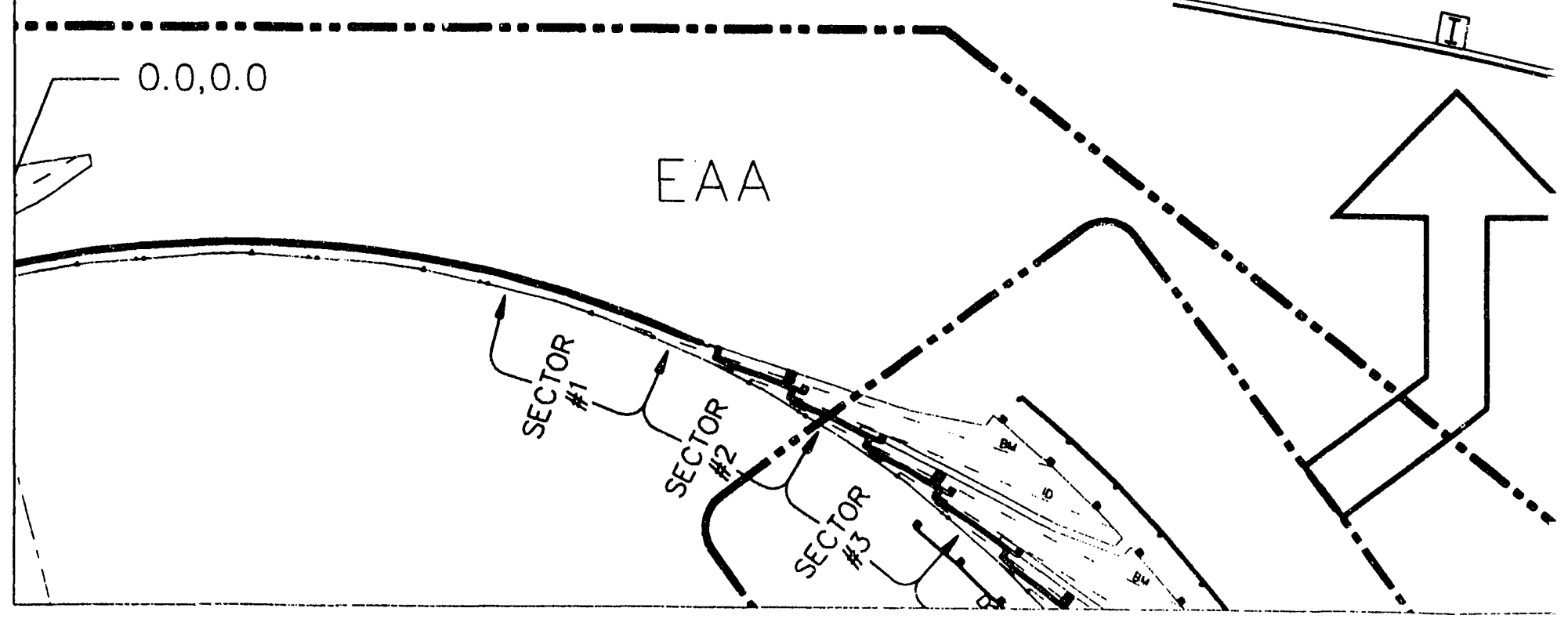

Figure 2 


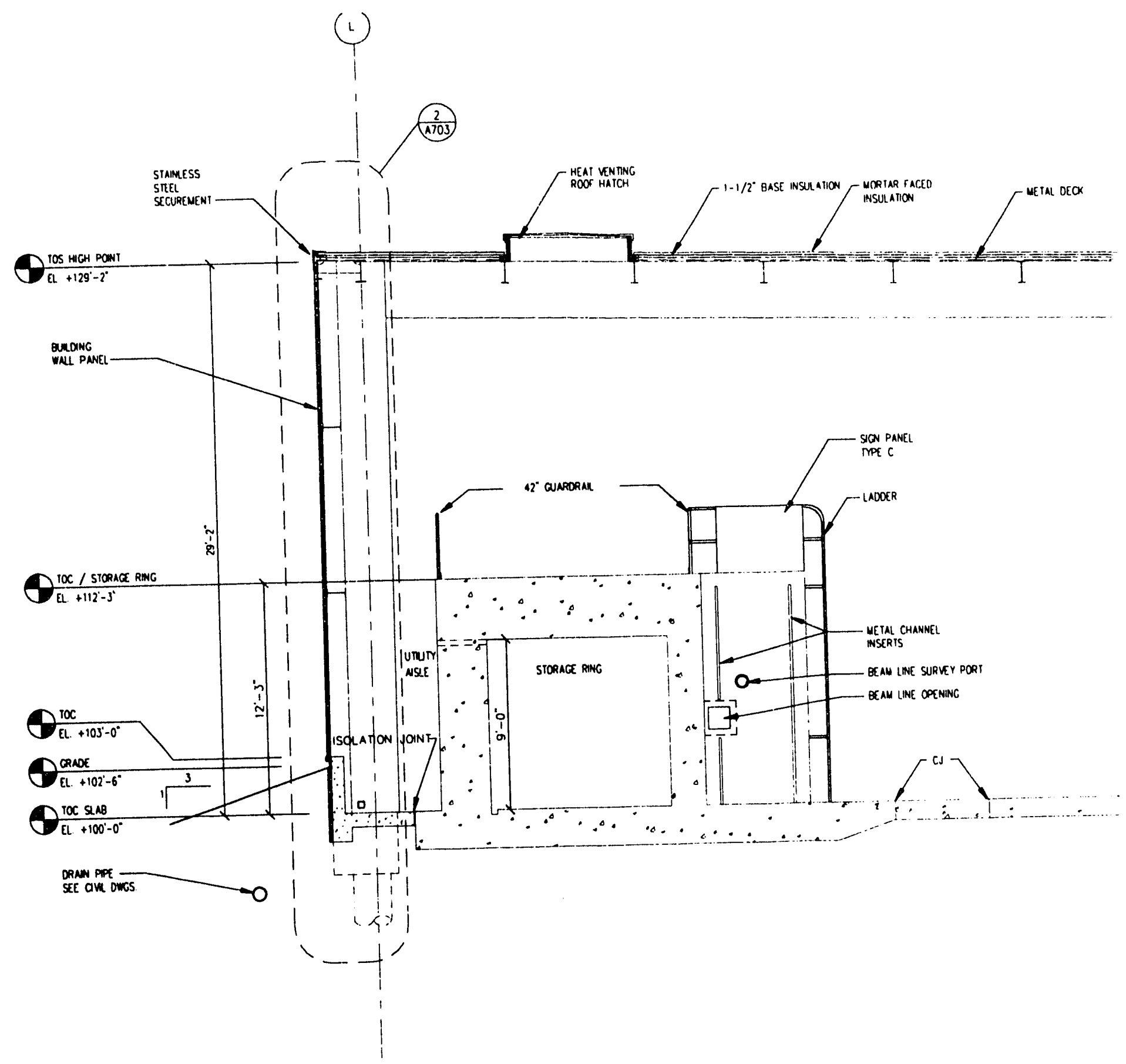




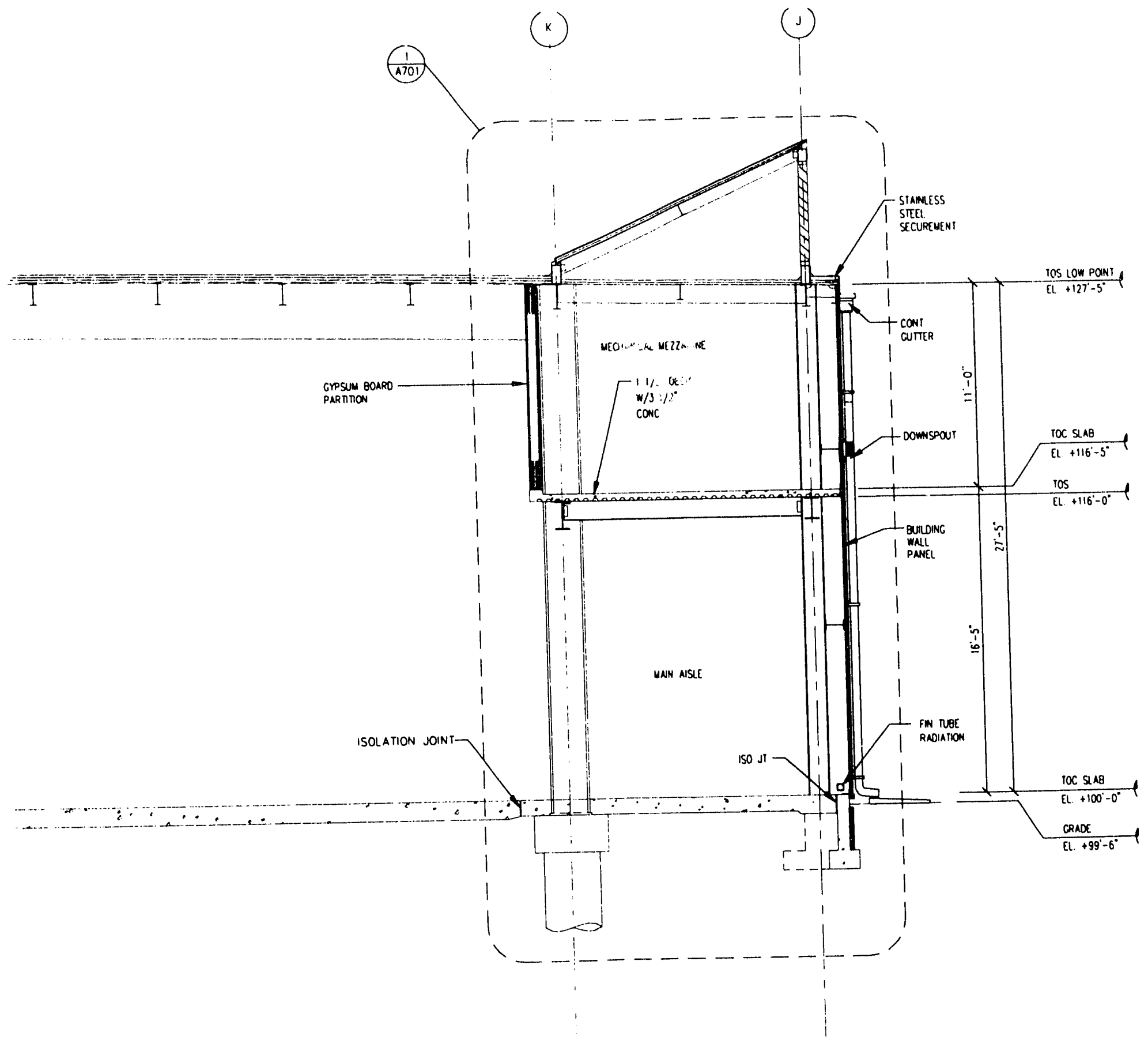




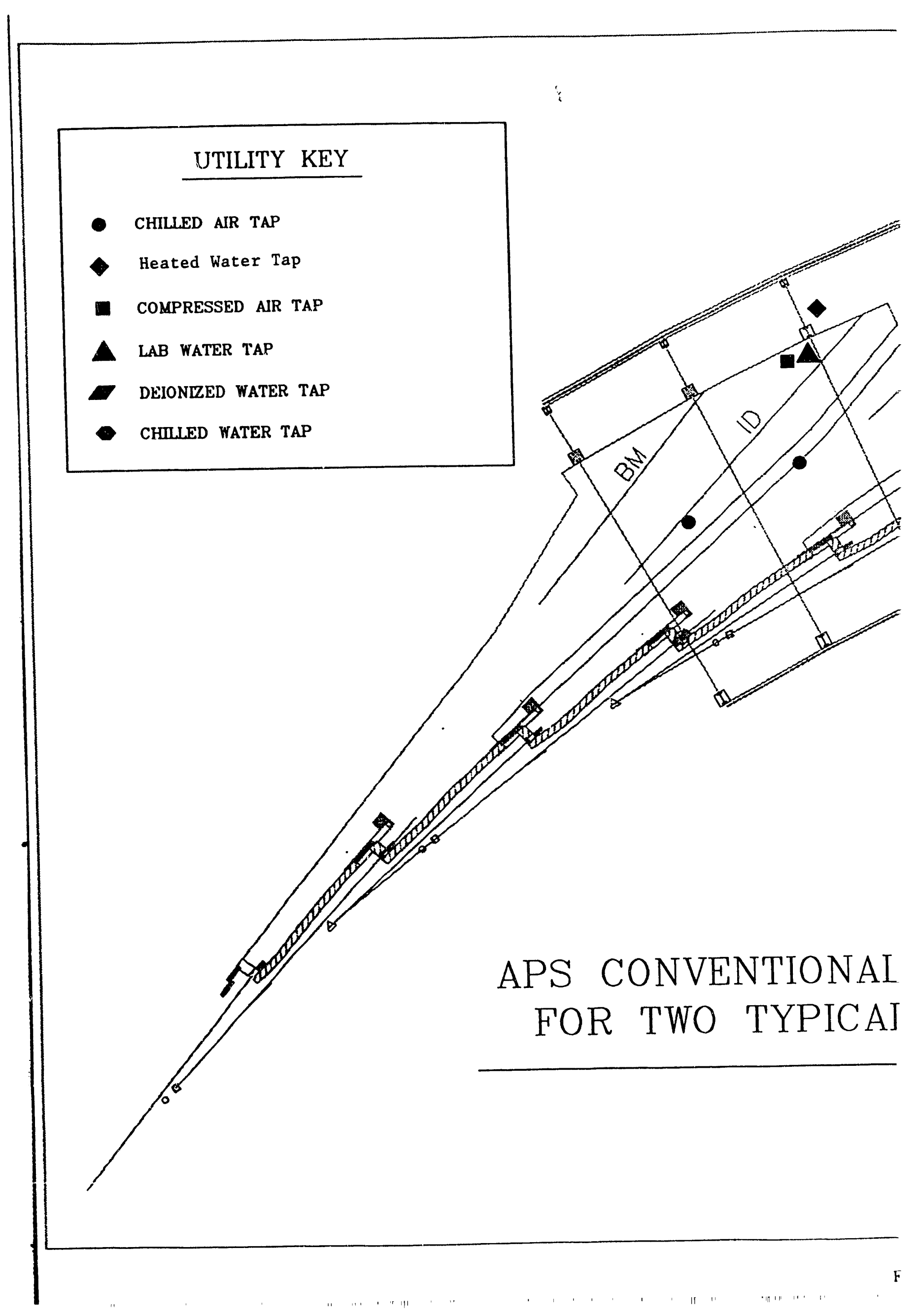




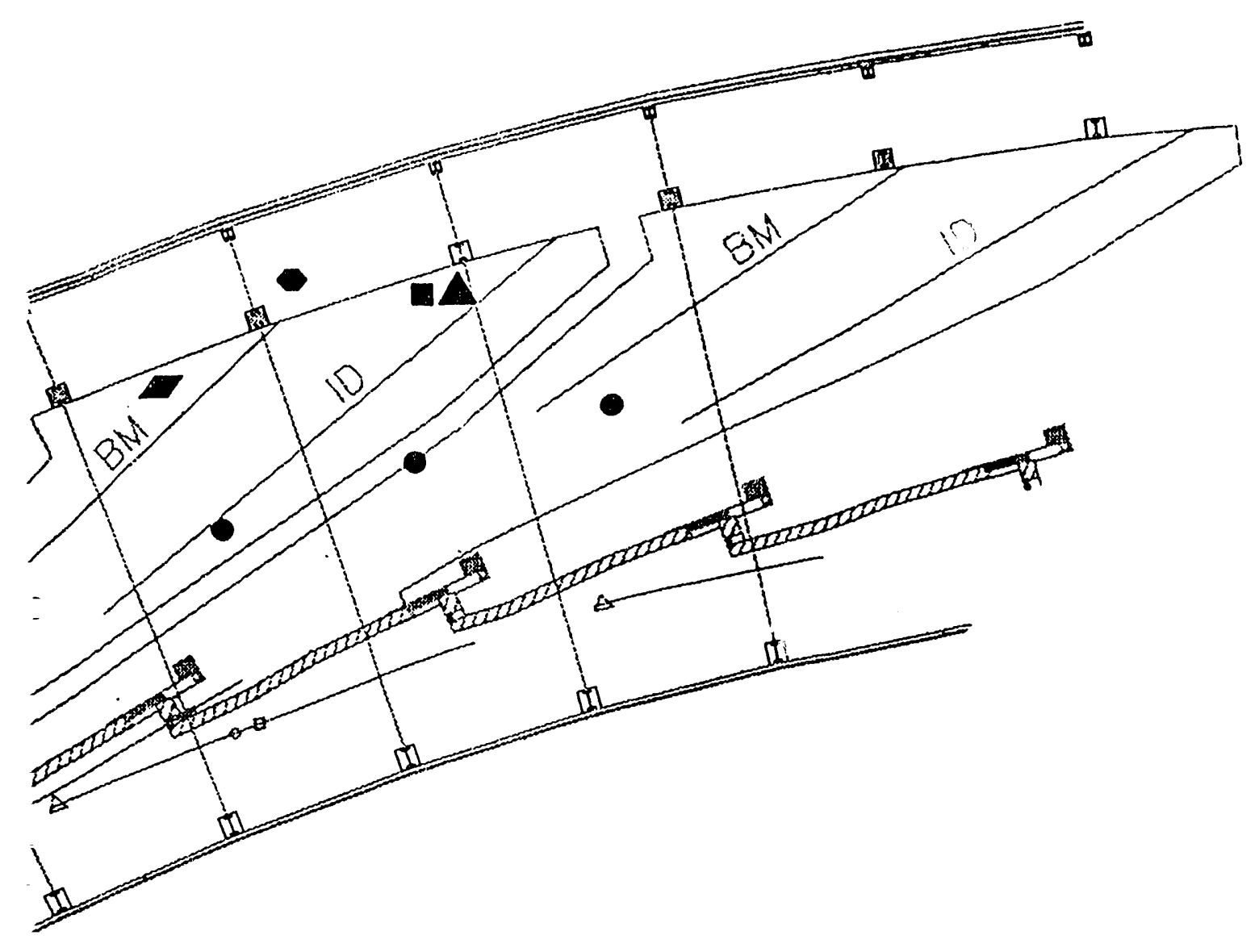

FACILITIES UTILITY LOCATIONS EXPERIMENT HALL SECTORS

\author{
NO SCALE
}



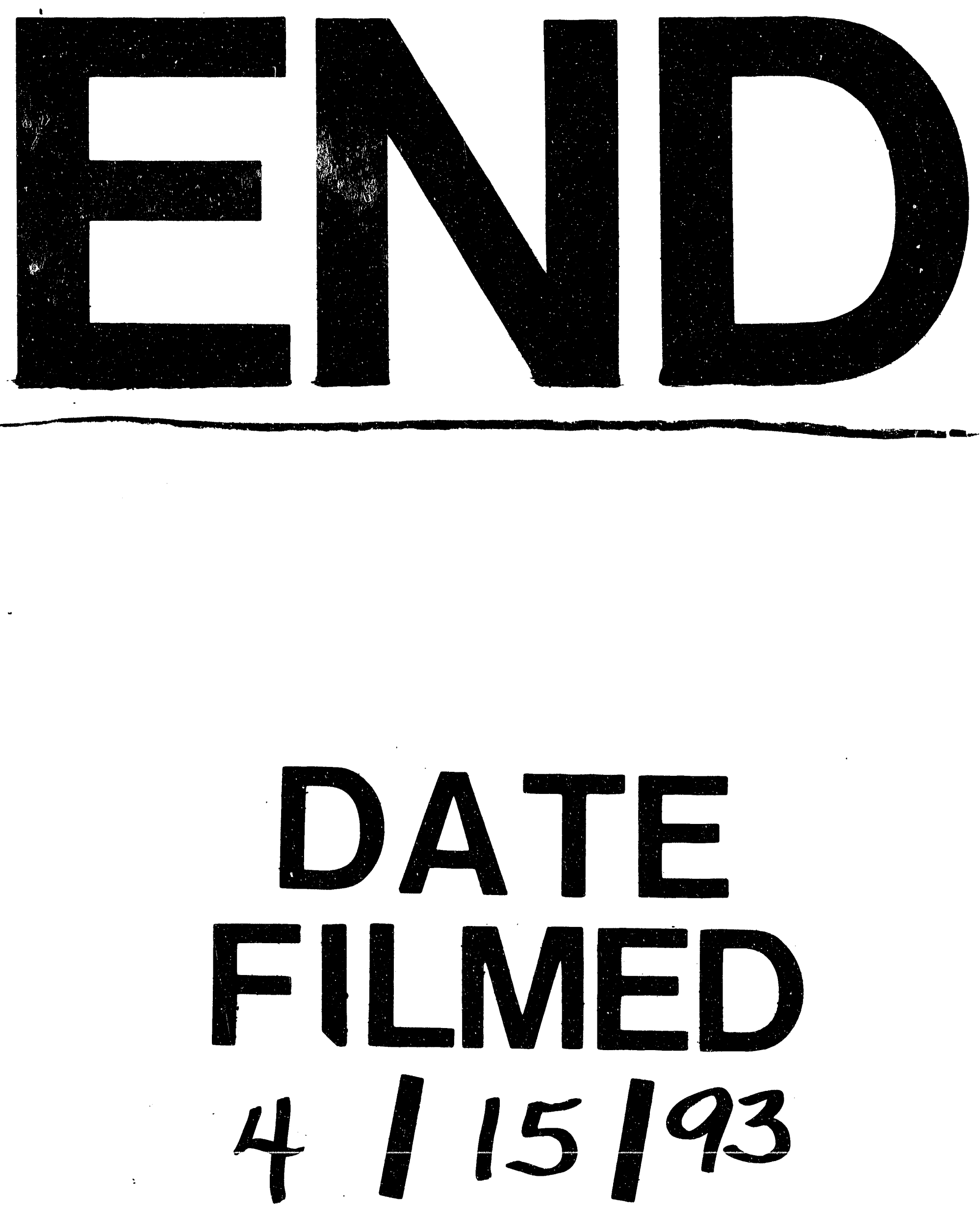
